\title{
Age at diagnosis of autism spectrum disorders: is there an association with socioeconomic status and family self-education about autism?
}

\author{
This article was published in the following Dove Press journal: \\ Neuropsychiatric Disease and Treatment \\ 6 July 2016 \\ Number of times this article has been viewed
}

\author{
Michal Hrdlicka' \\ Maria Vacova' \\ Hana Oslejskova ${ }^{2}$ \\ Veronika Gondzova ${ }^{2}$ \\ Iveta Vadlejchova ${ }^{3}$ \\ Jana Kocourkova' \\ Jiri Koutek' \\ Iva Dudova'
}

'Department of Child Psychiatry, Charles University Second Faculty of Medicine and University Hospital Motol, Prague, ${ }^{2}$ Department of Child Neurology, Masaryk University Faculty of Medicine and University Hospital, Brno, ${ }^{3}$ Child Psychiatry Clinic, Chomutov, Czech Republic
Correspondence: Michal Hrdlicka Department of Child Psychiatry, Charles University Second Faculty of Medicine and University Hospital Motol, $\vee$ Uvalu 84, 15006 Prague, Czech Republic Tel +420 224433400 Fax +420 224433420

Email michal.hrdlicka@lfmotol.cuni.cz
Background: The marked increase in autism spectrum disorders (ASD) prevalence has stimulated worldwide interest in exploring broader circumstances of care of autistic children, including the role of socioeconomic status (SES) and family information on autism.

Methods: Our sample comprised of 160 children who participated in a diagnostic examination focused on autism, and their parents who completed a simple descriptive questionnaire focusing on the family situation as well as family self-education about autism. The diagnosis of ASD was confirmed in 120 children ( $75 \%$ of the sample; 94 boys, 26 girls) with mean age $6.2 \pm 2.7$ years (median 5.3, range 2.2-17.2 years). In 71 autistic patients (59.2\%), a diagnosis of mental retardation was also established.

Results: The age at diagnosis of ASD correlated negatively with maternal $(P=0.014)$ and paternal $(P=0.002)$ ages at the time of birth of the ASD child as well as with paternal $(P=0.002)$ and maternal $(P=0.050)$ education. The age at diagnosis of ASD did not correlate with family SES. Mothers were significantly more active in seeking information on autism than fathers or both parents equally ( 80 vs 9 vs 28 cases, respectively; $P<0.001$ ). The mean number of information sources on autism was $3.5 \pm 1.8$ with a range $0-9$. The mean number of resources did not differ among the three SES groups ( 3.50 vs 3.49 vs 4.25 , respectively; $P=0.704)$. The mean number of sources did not correlate with the age at diagnosis of ASD. The most often used sources were the Internet (81.7\%), followed by psychologists $(48.3 \%)$, books $(46.7 \%)$, and child and adolescent psychiatrists (43.3\%).

Conclusion: An earlier diagnosis of ASD is associated with higher parental age at birth and higher parental education but not with family SES or number of family information sources.

Keywords: autism spectrum disorders, early diagnosis, socioeconomic status, parental education, parental information

\section{Introduction}

For many decades, autism was considered to be a rare condition. However, the reported prevalence of autism spectrum disorders (ASD) has considerably increased during the past decade, with recent estimates in the range of $1 \%-1.5 \%$. ${ }^{1,2}$ The marked increase in ASD prevalence has stimulated worldwide interest in exploring broader circumstances of care of autistic children. A number of studies have examined the role of socioeconomic status (SES) and family self-education about autism relative to the age of the child at the time of autism diagnosis.

Data from the US indicate that higher family SES and higher parental education levels are associated with an earlier autism diagnosis and higher autism prevalence. ${ }^{3-7}$ Parents and caregivers of ASD children with higher household incomes, as well as 
parents and caregivers with less education, were more likely to report greater satisfaction with the diagnostic processes used by the schools that their children attended. ${ }^{8}$ Associations were also found between higher SES and a family residing in an ASD hotspot (ie, localized geographical area associated with increased relative risk of ASD). ${ }^{9}$ In a Canadian study, household income accurately predicted intellectual disability status in $67 \%$ of autistic children. The lower the household income, the greater was the probability of meeting intellectual disability criteria. ${ }^{10}$

Similar to the US studies, higher SES was found to be a possible risk factor for autism in India, ${ }^{11}$ but not in the $\mathrm{UK}^{12}$ or in Thailand. ${ }^{13}$ Additionally, parental education was also not associated with autism risk in the UK. ${ }^{13}$ A Danish study showed no significant association between risk of autism on the one hand and SES and maternal education on the other hand (paternal education was not analyzed). ${ }^{14}$ However, markedly different results came from Sweden. Children of families with lower SES and of parents with manual labor occupations were at higher risk of ASD. No important relationships with parental education levels were observed. ${ }^{15}$

A systematic review of epidemiological surveys of ASD identified over 600 studies, including studies in local languages. The reviewed evidence did not support differences in ASD prevalence by geographic region, nor was there a strong impact of ethnic, cultural, or socioeconomic factors. ${ }^{16}$ Another comprehensive review, focusing on the age at ASD diagnosis and limited to studies published in English, identified 42 studies between 1990 and 2012. Factors associated with earlier diagnosis included higher SES, symptom severity, and greater parental concern about initial symptoms. ${ }^{17}$

Greater awareness of autism has been suggested as one of the factors influencing the increase in ASD prevalence. ${ }^{18}$ This may result in earlier and more frequent contacts between the family of a potential ASD child and health professionals. Thus, information sources on autism have increasingly become a topic of research interest in the past 2 decades. In 1999, British parents most frequently reported professionals as their source of information, although other parents and voluntary organizations were also mentioned. ${ }^{19}$ However, American parents reported 6 years later that the most frequent source of information was books $(88 \%)$, followed by the Internet $(86 \%)$ and other parents $(72 \%) .{ }^{20}$ On average, parents reported getting information about ASD from nearly seven different sources (mean 6.9; range $0-15)$. The total number of information sources also differed relative to parental or family income, with those in lower income groups (mean 5.9) using fewer information sources than either middle (mean 7.0) or upper (mean 7.2) income groups.

The main problem with the Internet serving as an information source is the extreme range in quality and reliability. US research found that websites with a "gov" top-level domain were significantly more likely to be of higher quality than websites with a commercial oriented top-level domain (eg, ".com" or ".org"). ${ }^{21}$ Research focused on websites of advocacy groups found that the majority (61\%) of the claims about treatment safety and efficacy were unsubstantiated. ${ }^{22}$ Instead, a range of rhetorical strategies were used to imply scientific support. Many websites did not meet criteria for quality health information and failed to cite evidence supporting described interventions. ${ }^{23}$

Regarding the situation in the Czech Republic, the first systematic diagnostic programs for autism were launched in the late 1990s. Two older studies reported a mean age at diagnosis of 9.1 years in $2004^{24}$ and 6.8 years in $2007 .{ }^{25}$ No specific studies on the prevalence of autism or on the socioeconomic factors associated with the age at ASD diagnosis have been conducted in the Czech Republic.

The aims of our study were to determine if family situation, including SES and access to information resources on autism, influenced the age at diagnosis of ASD in daily clinical practice in the Czech Republic.

\section{Methods \\ Questionnaire}

We created a simple descriptive questionnaire focusing on two topics: 1) general family situation and 2) family selfeducation about autism.

In the first part, we collected family information including 1) parental ages at the time of the examination and age and at the time of birth of the ASD-affected child, 2) educational level of parents, 3) household, 4) marital status, and 5) family SES. We divided the participant families into three SES groups based on Czech State legal definitions at the time the study was initiated. These definitions provide clear upper limits for low income and clear lower limits for high income families.

Low family SES: The total family income was below 2.4 multiples of the "Living Minimum Amount"; the family gets, according to this criterion, a financial allowance from the state for each child.

Middle family SES: Family income exceeds criterion A, but is less than criterion $\mathrm{C}$.

High family SES: At least one of the parents has an income of at least four multiples of the average salary in the Czech 
Republic (ie, 100,000 Czech crowns at minimum), or the sum of the incomes of both parents exceeds this amount.

In the second part, parents were questioned about whether they came to the examination with the expectation that their child had autism and whether they had sought information about autism prior to the examination. They were asked to identify all their information sources on autism and specify the number of sources they used in self-education. Multiple entries were allowed. They could choose from the following: 1) pediatrician; 2) child and adolescent psychiatrist; 3) physician of other specialty; 4) psychologist; 5) school nurse from a nursery school, school teacher, or special education teacher; 6) Internet; 7) books; 8) media (television, newspapers, journals); 9) people with similar problems in the family; and 10) other sources.

Finally, we asked the parents who had been more active in seeking information on autism whether or not they were satisfied with the information they had found on autism.

\section{Sample}

Responders were parents of 160 children (mean age at examination $6.5 \pm 2.9$ years; 123 boys, 37 girls) who attended a diagnostic examination focused on autism. The examination took place at three facilities: the Department of Child Psychiatry, University Hospital Motol, Prague (132 cases); the Department of Child Neurology, University Hospital, Brno (19 cases); and the Child Psychiatry Clinic, Chomutov (nine cases). Families were consecutively recruited from November 2012 to January 2016. The study was approved by the Multicentre Ethics Committee of the University Hospital Motol, and the Multicentre Ethics Committee of the University Hospital Brno. Parents who agreed to participate in the study also signed informed consents.

The questionnaires were completed, in the vast majority of cases, by mothers $(\mathrm{N}=142 ; 88.8 \%)$. Fathers completed the questionnaires in 16 cases $(10.0 \%)$, while "other" caregivers completed the questionnaires in two cases $(1.2 \%)$.

The International Classification of Diseases, 10th Edition, ${ }^{26}$ was used to make a clinical diagnosis, and experienced clinicians with expertise in the autism diagnosis were involved in the study. The diagnosis was further supported using age-appropriate modules from the Autism Diagnostic Observation Schedule ${ }^{27}$ and/or the Autism Diagnostic Interview - Revised ${ }^{28}$ in the Department of Child Psychiatry, or by the Autism Diagnostic Interview - Revised alone in the Department of Child Neurology. A diagnosis of ASD was confirmed in 120 children (75\% of the sample; 94 boys, 26 girls), and only this particular subgroup was used in the analysis that is presented in the "Results" section.
The mean age at examination of children with a confirmed ASD diagnosis was $6.2 \pm 2.7$ years (median 5.3, range 2.2-17.2 years). Diagnoses according International Classification of Diseases, 10th Edition included 88 patients with childhood autism, 24 patients with atypical autism, seven patients with Asperger syndrome, and one patient with other childhood disintegrative disorder. In 71 autistic patients (59.2\%), a diagnosis of mental retardation (MR) was also established. Of these, $35.2 \%$ had mild MR, 31\% moderate MR, 2.8\% severe MR, and 31\% unspecified MR.

The diagnosis in 40 children, where the ASD diagnosis was ruled out, included specific developmental disorders of speech and language (15 cases), hyperkinetic disorder (eleven cases), MR (eleven cases), abnormal personality development (four cases), and hyperkinetic conduct disorder (two cases). Other mixed disorders of conduct and emotions, phobic anxiety disorder of childhood, combined vocal and multiple motor tic disorder, and adjustment disorder were represented by one case of each. Several patients suffered from combined diagnoses.

\section{Statistics}

Statistical analysis was performed using the Statistical Package for the Social Sciences, v22 (IBM Corporation, Armonk, NY, USA). Descriptive statistics for the sample were used. The Spearman's correlation analysis was used to explore relationships between the age at diagnosis and parental education and family SES (ie, ordinal data). The Pearson's correlation analysis was used to explore relationships between the age at diagnosis and parental age at the time of birth of the affected child and the mean number of information sources used for self-education about autism (ie, continuous data).The one-sample chi-square test was used to compare activities of family members in seeking information about autism. The Mann-Whitney independent samples $U$ test was used for comparison of the number of information sources between families who suspected ASD and those who did not. The Kruskal-Wallis independent samples test was used for comparison of the number of information sources relative to the three SES groups.

\section{Results}

\section{Family demographic and socioeconomic status}

Data on the demographic and SES of families are presented in Table 1. The age at diagnosis of ASD correlated negatively with maternal and paternal ages at the time of birth of the affected child as well as with paternal and maternal education; that is, an earlier diagnosis of ASD was associated 
Table I Family characteristics of the sample $(n=\mid 20)$

\begin{tabular}{ll}
\hline Variables & $\begin{array}{l}\text { Mean ( } \pm \text { SD, range) } \\
\text { or frequency }(\%)\end{array}$ \\
\hline Maternal & $30.2( \pm 5.2,19.4-43.8)$ \\
Age at birth of ASD child (years) & $36.4( \pm 5.3,25.1-49.0)$ \\
Age at ASD examination (years) & \\
Education & 1 I $(9.2)$ \\
Elementary & $86(71.7)$ \\
High school & $23(19.2)$ \\
University & \\
Paternal & $33.4( \pm 6.5,20.3-62.3)$ \\
Age at birth of ASD child (years) & $39.6( \pm 6.3,26.0-67.2)$ \\
Age at ASD examination (years) & \\
Education & $3(2.5)$ \\
Elementary & $78(65.0)$ \\
High school & $35(29.2)$ \\
University & $4(3.3)$ \\
Unknown & \\
Family socioeconomic status & $29(24.2)$ \\
Low & $87(72.5)$ \\
Middle & $4(3.3)$ \\
High & $86(71.7)$ \\
Parents & $34(28.3)$ \\
Live together & \\
Separated or divorced &
\end{tabular}

Abbreviations: SD, standard deviation; $A S D$, autism spectrum disorder; $n$, number of children.

with higher parental age at birth and higher parental education. The age at diagnosis of ASD did not correlate with family SES (Table 2).

\section{Parental views and activity}

The majority of families (75.8\%) came to the diagnostic examination with the opinion that their child was autistic: 47 parents (39.2\%) gave the answer "definitely agree" and 44 parents (36.7\%) gave the answer "slightly agree". Only 16 parents (13.3\%) answered "slightly disagree" and one family $(0.8 \%)$ responded "definitely disagree". Twelve families

Table 2 Correlation between age at diagnosis of autism spectrum disorders and sociodemographic variables

\begin{tabular}{|c|c|c|c|c|}
\hline \multirow[t]{2}{*}{ Variables } & \multicolumn{4}{|c|}{$\begin{array}{l}\text { Age at diagnosis of autism spectrum } \\
\text { disorders }\end{array}$} \\
\hline & $\mathbf{N}$ & $\begin{array}{l}\text { Type of } \\
\text { correlation }\end{array}$ & $\begin{array}{l}\text { Correlation } \\
\text { coefficient }\end{array}$ & $P$-value \\
\hline Maternal age at delivery & 120 & Pearson's & -0.224 & 0.014 \\
\hline Maternal education & 120 & Spearman's & -0.180 & 0.050 \\
\hline Paternal age at delivery & 117 & Pearson's & -0.283 & 0.002 \\
\hline Paternal education & 116 & Spearman's & -0.286 & 0.002 \\
\hline Family socioeconomic status & 120 & Spearman's & -0.082 & 0.371 \\
\hline
\end{tabular}

Abbreviation: $\mathrm{N}$, number of cases in the correlation.
(10.0\%) reported that there was no preestablished opinion within the family.

The vast majority of families $(114 / 120,95 \%)$ sought information on autism prior to the diagnostic procedure. Mothers were significantly more active in seeking information on autism than fathers or both parents equally $(80 \mathrm{vs}$ 9 vs 28 cases, respectively; $\chi^{2}=69.282, d f=2, P<0.001$ ). Three families did not respond to the question. Thirty-nine responders (32.5\%) considered the information they found on autism to be sufficient; 80 responders $(66.7 \%)$ reported that they found the information inadequate. In one case $(0.8 \%)$, the answer was missing.

\section{Information sources on autism}

The mean number of sources on autism was $3.5 \pm 1.8$ (range 0-9), and the median number of sources was 3. Taking into account only those families who expressed a defined opinion about whether their child was autistic or not $(\mathrm{n}=108)$, it was found that the mean number of sources was significantly higher in parents who had suspected ASD compared to those who had not (3.75 vs 2.82, respectively, $U=524.0, P=0.042$ ). The mean number of resources did not differ among the three SES groups ( 3.50 vs 3.49 vs 4.25 , respectively; $H=0.703, d f=2$, $P=0.704)$. The mean number of sources did not correlate with the age at diagnosis of ASD ( $r=-0.145, P=0.118)$.

Table 3 specifies sources of information. The most often used information sources were found on the Internet $(81.7 \%)$, followed by psychologists (48.3\%), books (46.7\%), and child and adolescent psychiatrists $(43.3 \%)$. In the subgroup of physicians with other specialties, neurologists and pediatric neurologists were the most common (12/20, 60.0\%).

\section{Discussion}

Our finding that higher education of both parents correlated with a younger age at diagnosis of ASD agrees with studies

Table 3 Sources of family information about autism

\begin{tabular}{lll}
\hline Source & $\begin{array}{l}\text { Number } \\
\text { of answers }\end{array}$ & $\begin{array}{l}\text { Frequency } \\
\text { (\%) }\end{array}$ \\
\hline Internet & 98 & 81.7 \\
Psychologist & 58 & 48.3 \\
Books & 56 & 46.7 \\
Child and adolescent psychiatrist & 52 & 43.3 \\
Nurse in a nursery school, school & 38 & 31.7 \\
teacher, special education teacher & & \\
Media (television, newspapers, journals) & 26 & 21.7 \\
Pediatrician & 26 & 21.7 \\
Physician of other specialty & 20 & 16.7 \\
Other sources & 18 & 15.0 \\
Persons with similar family problems & 17 & 14.2 \\
\hline
\end{tabular}


published in the US. ${ }^{3-7}$ On the other hand, our finding that family SES was not associated with an earlier diagnosis of ASD was inconsistent with several US studies ${ }^{3-7}$ and also with the results from a comprehensive review by Daniels and Mandell. ${ }^{17}$ Our results on SES are more in line with findings from certain developed European countries with general health insurance and an open health care system, eg, Denmark. ${ }^{14}$ Significant negative correlations between the age at ASD diagnosis and parental age at delivery and parental education were not surprising - older and better educated parents are obviously more experienced and able to manage health care of their children more efficiently. However, it must be noted that the correlation coefficients (range 0.180-0.286) indicated a rather small effect size for all variables that were significantly correlated with the age at diagnosis, according to the Cohen's classification. ${ }^{29}$

Czech parents were active in seeking information about autism prior to the diagnostic examination (95\% of the sample). It was of no surprise that mothers were significantly more active in seeking information than fathers; even so, our findings showed that with regard to fathers the numbers were unexpectedly very low $(\mathrm{N}=9,7.7 \%)$. In certain ways our results correspond with a study by Johnson and Simpson, ${ }^{30}$ who found that $63.5 \%$ of mothers with autistic children reported having a spouse who had not been willing to participate in some type of research survey. According to the authors, this indifference may indicate a lack of paternal involvement not only in self-education regarding autism but also in the day-to-day care of children with ASD.

The mean number of information sources used for selfeducation about autism was lower in Czech families (3.5) compared to US families (6.9), which was reported in a study by Mackintosh et al. ${ }^{20}$ Unlike the Mackintosh et al study, the total number of information sources did not differ among the SES groups defined in our study. However, the passing of 11 years between publication of the Mackintosh et al study and our study probably did influence the preference of information sources. In the US study, books were the most often used resource (88\%), followed closely by the Internet $(86 \%)$ and then by other parents having children with ASD $(72 \%) .{ }^{20}$ In our study, the Internet was the main source of information (81.7\%), whereas books came in third place with $46.7 \%$. Additionally, the number of sources of information coming from those with similar family problems was also very low compared to the US study (14.2\% vs $72 \%)$. The difference may reflect different social and cultural traditions in both countries. Of particular interest was the low involvement of pediatricians in providing families with information on autism $(21.7 \%)$, which may point to a specific gap in the Czech system of primary pediatric care.

Our data also pointed to a decrease in both the age at diagnosis and proportion of intellectual disability in ASD individuals over time, generally speaking. In two Czech studies from the 2000s, mean ages at diagnosis were 9.1 years ${ }^{24}$ and 6.8 years, ${ }^{25}$ whereas the mean age was 6.2 years in the current study. In the 1990 s, approximately $75 \%-80 \%$ of children with autism were described as mentally retarded, ${ }^{31}$ and in a study from 2004, the number remained high, at $79.7 \% .{ }^{24}$ However, a recent meta-analysis by Elsabbagh et al reported that the proportion of participants with normal IQ was in the range of $15.6 \%-86.7 \%$ for autistic disorder and $45 \%-85.3 \%$ for pervasive developmental disorders. ${ }^{16}$ Our current study found the proportion of children with normal IQ to be $40.8 \%$, which corresponds with Elsabbagh et al meta-analysis. ${ }^{16}$

A possible limitation of our study involves the relatively few families in our study that reported being in the high SES group $(3.3 \%)$, which could have led to a misrepresentation of this group. One explanation could be that the design of our study did not provide anonymous data collection; thus, some families might have not been willing to reveal their true SES. Alternatively, it is possible that families with higher incomes may prefer diagnostic examinations in private facilities, which exist outside of the general health insurance system; all three facilities that took part in this study were part of the general health insurance system. Regrettably, objective means to verify either of these speculative explanations were not available.

\section{Conclusion}

Earlier diagnosis of ASD was associated with higher parental age at the time of birth of the ASD-affected child and higher parental education. The age at diagnosis of ASD did not correlate with family SES. Mothers were significantly more active in seeking information on autism than fathers or both parents equally. An earlier diagnosis was not associated with the number of information sources that the family used for self-education about ASD.

\section{Acknowledgments}

This work was supported by the Project (Ministry of Health, Czech Republic) for Conceptual Development of Research Organization 00064203 (University Hospital Motol, Prague, Czech Republic), and by the Ministry of Health of the Czech Republic, grant number 16-31754A. All rights are reserved. The authors would like to thank Prof Tomas Urbanek, for 
statistical consultation, and Thomas Secrest, for his assistance with the English version of the manuscript.

\section{Disclosure}

The authors report no conflicts of interest in this work.

\section{References}

1. Baron-Cohen S, Scott FJ, Allison C, et al. Prevalence of autism-spectrum conditions: UK school-based population study. Br J Psychiatry. 2009; 194:500-509.

2. Baio J. Prevalence of autism spectrum disorders among children aged 8 years - Autism and Developmental Disabilities Monitoring Network, 11 sites, United States, 2010. MMWR. 2014;63(2):1-21.

3. Durkin MS, Maenner MJ, Meaney JM, et al. Socioeconomic inequality in the prevalence of autism spectrum disorder: evidence from a U.S. cross-sectional study. PLoS ONE. 2010;5:e11551.

4. Fountain C, King MD, Bearman PS. Age of diagnosis for autism: individual and community factors across 10 birth cohorts. J Epidemiol Community Health. 2011;65:503-510.

5. King MD, Bearman PS. Socioeconomic status and the increased prevalence of autism in California. Am Sociol Rev. 2011;76:320-346.

6. Thomas P, Zahorodny W, Peng B, et al. The association of autism diagnosis with socioeconomic status. Autism. 2012;16:201-213.

7. Mazurek MO, Handen BL, Wodka EL, Nowinski L, Butter E, Engelhardt CR. Age at first autism spectrum diagnosis: the role of birth cohort, demographic factors, and clinical features. J Dev Behav Pediatr. 2014;35:561-569.

8. Hidalgo NJ, McIntyre LL, McWhirter EH. Sociodemographic differences in parental satisfaction with an autism spectrum disorder diagnosis. J Intellect Dev Disabil. 2015;40:147-155.

9. Bakian AV, Bilder DA, Coon H, McMahon WM. Spatial relative risk pattern of autism spectrum disorders in Utah. J Autism Dev Disord. 2015; 45:988-1000.

10. Rivard M, Terroux A, Mercier C, Parent-Boursier C. Indicators of intellectual disabilities in young children with autism spectrum disorders. J Autism Dev Disord. 2015;45:127-137.

11. George B, Padman MSR, Nair MKC, Leena ML, Russell PSS. CDC Kerala 12: sociodemographic factors among children (2-6 y) with autism - a case control study. Indian J Pediatr. 2014;81(Suppl 2):S129-S132.

12. Sun X, Allison C, Auyeung B, Baron-Cohen S, Brayne C. Parental concerns, socioeconomic status, and the risk of autism spectrum conditions in a population-based study. Res Dev Disabil. 2014;35:3678-3688.

13. Khaiman C, Onnuam K, Photchanakaew S, Chonchaiya W, Suphapeetiporn K. Risk factors for autism spectrum disorder in the Thai population. Eur J Pediatr. 2015;174:1365-1372.

14. Larsson HJ, Eaton WW, Madsen KM, et al. Risk factors for autism: perinatal factors, parental psychiatric history, and socioeconomic status. Am J Epidemiol. 2005;161:916-925.
15. Rai D, Lewis G, Lundberg M, et al. Parental socioeconomic status and risk of offspring autism spectrum disorders in a Swedish populationbased study. J Am Acad Child Adolesc Psychiatry. 2012;51:467-476.

16. Elsabbagh M, Divan G, Koh YJ, et al. Global prevalence of autism and other pervasive developmental disorders. Autism Res. 2012;5: 160-179.

17. Daniels AM, Mandell DS. Explaining differences in age at autism spectrum disorder diagnosis: a critical review. Autism. 2014;18:583-597.

18. Weintraub K. Autism counts. Nature. 2011;479:22-24.

19. Pain H. Coping with a child with disabilities from the parents' perspective: the function of information. Child Care Health Dev. 1999;25: 299-312.

20. Mackintosh VH, Myers BJ, Goin-Kochel RP. Sources of information and support used by parents of children with autism spectrum disorders. J Dev Disabil. 2005;12:41-51.

21. Reichow B, Halpern JI, Steinhoff TB, Letsinger N, Naples A, Volkmar F. Characteristics and quality of autism websites. J Autism Dev Disord. 2012;42:1263-1274.

22. Di Pietro NC, Whiteley L, Mizgalewicz A, Illes J. Treatment for neurodevelopmental disorders: evidence, advocacy and the Internet. J Autism Dev Disord. 2013;43:122-133.

23. Grant N, Rodger, Hoffmann T. Evaluation of autism-related health information on the web. J Appl Res Intellect Disabil. 2015;28:276-282.

24. Hrdlicka M, Komarek V, Propper L, et al. Not EEG abnormalities but epilepsy is associated with autistic regression and mental functioning in childhood autism. Eur Child Adolesc Psychiatry. 2004;13:209-213.

25. Oslejskova H, Kontrova I, Foralova R, Dusek L, Nemethova D. The course of diagnosis in autistic patients: the delay between recognition of the first symptoms by parents and correct diagnosis. Neuro Endocrinol Lett. 2007;28:895-900.

26. World Health Organization. International Classification of Diseases. 10th ed. Geneva: WHO; 1992.

27. Lord C, Risi S, Lambrecht L, et al. The Autism Diagnostic Observation Schedule - Generic: a standard measure of social and communication deficits associated with the spectrum of autism. J Autism Dev Disord. 2000;30:205-223.

28. Lord C, Rutter M, LeCouteur A. Autism Diagnostic Interview - Revised: a revised version of a diagnostic interview for caregivers of individuals with possible pervasive developmental disorders. J Autism Dev Disord. 1994;24:659-685.

29. Cohen J. Statistical Power Analysis for the Behavioral Sciences. 2nd ed. Hillsdale: Lawrence Erlbaum Associates; 1988.

30. Johnson NL, Simpson PM. Lack of father involvement in research on children with autism spectrum disorder: maternal parenting stress and family functioning. Issues Ment Health Nurs. 2013;34:220-228.

31. Sadock BJ, Sadock VA. Kaplan and Sadock's Comprehensive Textbook of Psychiatry. 7th ed. Philadelphia: Lippincott Williams \& Wilkins; 1999.
Neuropsychiatric Disease and Treatment

\section{Publish your work in this journal}

Neuropsychiatric Disease and Treatment is an international, peerreviewed journal of clinical therapeutics and pharmacology focusing on concise rapid reporting of clinical or pre-clinical studies on a range of neuropsychiatric and neurological disorders. This journal is indexed on PubMed Central, the 'PsycINFO' database and CAS,

\section{Dovepress}

and is the official journal of The International Neuropsychiatric Association (INA). The manuscript management system is completely online and includes a very quick and fair peer-review system, which is all easy to use. Visit http://www.dovepress.com/testimonials.php to read real quotes from published authors. 